RUNNING HEAD: Neuropolitics: Twenty years later

\title{
Neuropolitics: Twenty years later
}

\author{
Darren Schreiber
}

University of Exeter

Correspondence:

Darren Schreiber

Department of Politics

University of Exeter

Mail Room, The Old Library

Prince of Wales Road

Exeter, Devon EX4 4SB

United Kingdom

Email: D.M.Schreiber@exeter.ac.uk

Correspondence: Darren Schreiber, Department of Politics, University of Exeter, Mail Room, The Old Library, Prince of Wales Road, Exeter, Devon EX4 4SB United Kingdom. Email: D.M.Schreiber@exeter.ac.uk 


\title{
Neuropolitics: Twenty years later
}

\begin{abstract}
Neuropolitics is the intersection of neuroscience and political science, which has the interdisciplinary goal of transforming both disciplines. This article reviews the past 20 years of work in the field, identifying its roots, some overarching themes (reactions to political attitudinal questions and candidates faces, identification of political ideology based on brain structure or reactivity to nonpolitical stimuli, and racial attitudes), and obstacles to its progress. I then explore the methodological and analytical advances that point the way forward for the future of neuropolitics. Though the field has been slow to develop compared with neurolaw and neuroeconomics, innovations look ripe for dramatically improving our ability to model political behaviors and attitudes in individuals and predict political choices in mass publics. The coming advancements, however, pose risks to our current norms of democratic deliberation and academics need to anticipate and mitigate these risks.
\end{abstract}

Key words: neuropolitics, social cognitive neuroscience, brain imaging, fMRI, neuroforecasting 
"In an earlier period, the behaviorist decree that subjective states lie beyond the realm of proper measurement gave Mannheim a justification for turning his back on measurement... Nevertheless, while rapid strides in the measurement of 'subjective' states have been achieved in recent decades, few would claim that the millennium has arrived ..." - Philip Converse ${ }^{1}$

While the millennium has arrived and passed, the progress on the measurement of subjective states is still in its early days and the "friendship" ${ }^{2}$ between neuroscience and politics is still in the acquaintance stage. Neuropolitics is a more recent manifestation of an inquiry into human nature stretching back thousands of years ${ }^{3}$. Converging lines of evidence have shown that our engagement with and creation of the political world we live in is related to our being human and having the brains that humans do. Our brains appear to be built for politics, a consequence of a three million year old cognitive arms race propelled by a need to manage our increasingly dynamic social complexity ${ }^{4}$.

Though Aristotle's ${ }^{5}$ claim that we are political animals has stood the test of time, it is clear that we are not the only political animals ${ }^{6}$. Many other species have the sophisticated brains needed to manage complex coalitional dynamics among non-kin. Chimpanzees and many other primates demonstrate interactions familiar to political scientists ${ }^{7}$. But it is not just our nearest cousins that show this ability: hyenas ${ }^{8}$ and dolphins ${ }^{9}$ illustrate the forces of convergent evolution with unusual brains and unusually complex coalitional dynamics.

But, a political science focused on any of these other species would be different from the field that has developed around the study of human politics over the past two millennia. This is true to at least some degree due to the way the human brain has evolved. Neuropolitics is a relatively new field connecting research in political science and neuroscience, which has the interdisciplinary goal of transforming both fields. If human nature is political, then studying our 
brain without considering its role in politics is just as flawed as ignoring the brain when studying politics.

This article begins by briefly recounting the historical opposition to investigations of the role of the brain and biology in politics along with noting some of the first attempts at drawing connections. In the next section, I note how the fields of cognitive science and neuroscience came together but were missing a tool that would enable investigations in a critical range of temporal and spatial scales. Soon after, functional magnetic resonance imaging (fMRI) provided that missing piece and the nascent research area rapidly coalesced into a field of study. The next section describes how studies of social cognition began to take advantage of brain imaging to illuminate functions of a variety of brain regions that had been previously underappreciated or understood in only a limited way.

After that I describe the first theoretical and then empirical discoveries as neuropolitics research began to be reported. I then contrast the development of neuropolitics with the far more prolific work in the adjacent fields of neurolaw and neuroeconomics. Finally, I review a range of promising new innovations in methods and analytical strategies that I expect will enable neuropolitics to move towards its potential and overcome some of the current constraints that hold back the field. It has been 20 years since I sketched out my first research proposal for the studies of political questions using functional imaging ${ }^{10}$. The field has developed substantially, but it still has the potential to go much further.

\section{Early impediments and first steps}

Resistance to connecting politics to the brain has deep historical and intellectual roots. Aristotle ${ }^{11}$ analogized the human mind to a blank writing tablet but did link the type of soul an entity had to its biology (i.e. humans have a rational soul, animals have a sensing soul, and plants 
have a vegetative soul). During the Renaissance, René Descartes' ${ }^{12}$ philosophy separated the mind from the body. And, just after Descartes, John Locke's ${ }^{13}$ expansion of Aristotle's analogy into a full-fledged argument about human nature shifted investigations in the social sciences for centuries away from embodied forms of cognition ${ }^{14}$. Locke's role in foreclosing a potential function for biology in human nature is ironic given that he was earlier part of an important group investigating the anatomy and architecture of the brain ${ }^{15}$.

While Sigmund Freud ${ }^{16}$ was similarly trained in neurology, even his early work emphasized functions of the mind over structures of the brain. Both psychoanalysis and later reactions to it like behaviorism ${ }^{17}$ directed focus away from biological explanations of psychological phenomena. For the psychoanalyst, experiences of the mind and their interpretations were central considerations. For the behaviorist, observations about responses to stimuli were the primary interest, regardless of which biological species happened to be doing the responding. Any potential interplay of biological factors in either of these dominant paradigms was put decidedly aside.

The behaviorist emphasis in the early to mid-20th century heavily influenced political science's agenda and approaches to political questions were often focused on observable behaviors such as voting or expressions of attitudes, rather than exploring a potential role for the brain or biology ${ }^{18}$. As rational choice theory migrated from economics to politics ${ }^{19}$, yet another impediment was laid for understanding how brains might influence political decision making. Anthony Downs' five-part definition of rationality, for example, gives no role for the potential emotional, biological, or neurological factors that might bend our political will.

Examinations of a potential connection between biology and politics was made particularly unpalatable for many in the mid-1900s given the role of biology in Nazi rhetoric 
justifying their atrocities ${ }^{20}$. However, by the 1970s some researchers had started using biological methods to investigate political questions. John Wahlke and Milton Lodge ${ }^{21}$ employed physiological measures of arousal to investigate political attitudes. Lindon Eaves and Hans Eysenck $^{22}$ showed that attitudes demonstrated evidence of biological heredity. And, in what may be the first study of neuropolitics, Roger Sperry and colleagues ${ }^{23}$ investigated attitudes towards political figures in both hemispheres of split-brain patients.

In most human brains, the corpus callosum is a bundle of white matter fibers that connect the left and right hemisphere and enable communication between them. In cases of severe epilepsy, this connection may be severed in order to reduce the symptoms of the disease, resulting in a split-brain. Sperry and his colleagues presented a range of stimuli, including photos of Hitler and Nixon, to only one eye at a time in order to evaluate whether both hemispheres of the brain were capable of reporting attitudes towards these political stimuli. While this type of work garnered a Nobel Prize for Sperry, it is important for neuropolitics as a reminder of the potential gains from using clinical cases and lesion studies in digging into our assumptions about political cognition. Much of our early knowledge about how the brain and mind function together came from studies of patients who had experienced damage to one region or another. While other tools have emerged and will continue to develop, the opportunities to untangle insights from clinical cases remain important.

\section{fMRI and the foundations of cognitive neuroscience}

A seminal paper by Patricia Churchland and Terry Sejnowski ${ }^{24}$ includes a figure that illustrates the tools available at the time that enabled the study of neuroscientific phenomena. The figure shows the temporal ( $\mathrm{X}$ axis) and spatial scales (Y axis) that those tools covered. Brain lesion studies, for instance, sit in the upper right hand side, covering a temporal scale of days to 
years and a spatial scale of millimeters to centimeters. While the illustration maps the spatial and temporal scales covered by the contemporary methods available in the 1980 s, the figure looks like a puzzle with a critical missing piece. There was simple no tool available to study the brain at the temporal scale from seconds to hours and the spatial scale from cubic millimeters to the whole brain. Despite this gap, the authors argued that there was a developing convergence that would undermine the conventional independence of neuroscience and cognitive science. In the following years, the new field of cognitive neuroscience emerged, but progress was dramatically accelerated as the new technique of functional magnetic resonance imaging (fMRI) arose, coming in like the perfect puzzle piece to fill in the hole that had been mapped out in the Churchland and Sejnowski paper.

Magnetic resonance imaging (MRI) devices create extremely powerful fields that provoke distinct patterns of magnetic flux around the protons that make up the hydrogen in the water within our body. Small differences in the polarization of these protons then enable the imaging of structures and differentiation of tissues within the human body ${ }^{25}$. While MRI creates static images of structure akin to a photograph, fMRI relies on a series of images in sequence like the frames of a film that allow researchers to detect change in cerebral blood flow over time.

Oxygenated blood is pumped to feed the brain and it has a slightly different magnetic signature when compared to the blood that has been deoxygenated as the brain's neural tissue absorbs this needed fuel from the supplied blood. The blood oxygen level dependent (BOLD) magnetic signal varies with shifts in the level of oxygen in the blood and changes from image to image as the brain functions and different neural regions require different levels of metabolic activity. Early neuroscience research, such as studies by Paul Broca ${ }^{26}$, had shown that certain cognitive functions appeared to be at least partially localized to particular brain regions. 
The first wave of fMRI studies suggested that there were changes in metabolic activity in specific brain areas as participants engaged in specific cognitive tasks. Thus, discrete mental functions could be associated with discrete brain structures. The effect on the new field of cognitive neuroscience was dramatic. As Peter Bandettini ${ }^{25}$ and others have shown, dozens, then hundreds, and then thousands of papers were soon being published using fMRI each year.

The temporal resolution of seconds to hours meant that many types of well-developed cognitive science and psychological studies could be replicated while participants were undergoing brain scanning. Though not able to obtain the millisecond precision of contemporary electroencephalogram (EEG) techniques, fMRI benefited from a spatial resolution of millimeters and could provide data for the full depth of the human brain, rather than merely inferences from the surface. Additionally, fMRI could be easily and ethically performed with healthy participants rather than requiring the injection of radioactive agents as in Positron Emission Tomography (PET) or relying on severe brain damage as lesion studies had. The combination of temporal resolution from seconds to hours, spatial resolution of millimeters across the whole brain, and the very low invasiveness and risks of the method provided an exciting and powerful new tool, which filled the gap highlighted by Churchland and Sejnowski ${ }^{24}$.

Just as fMRI was first developing, I first encountered this research in an article by functional imaging pioneer Marcus Raichle ${ }^{27}$ in Scientific American. The initial studies focused on replicating existing cognitive and perceptual studies and reinforcing existing theories of functional localization. A typical study involved having participants perform a new task while being imaged with fMRI and then rescanning them after they had practiced the task extensively. Such practice related paradigms had been employed in measures of cognition all the way back to the early work of F.C. Donders ${ }^{28}$, who measured the amount of time that tasks took in order to 
infer their cognitive complexity and demands. In a happy confirmation, brain imaging during language-related tasks, such as conjugating verbs in an unfamiliar language, involved the same region that Broca had identified in his lesion studies of people with language difficulties. Results across a wide range of tasks showed that additional oxygenated blood flowed into a region believed to be critical for that task when the task was relatively novel. With practice, the amount of time required for the task diminished and the blood flow to the involved region also decreased. Expertise appeared to demand less mental effort even as performance continued to improve.

My interest in brain imaging was spurred on as I read the work of Phillip Converse ${ }^{1}$, John Zaller ${ }^{29}$ and others for the first time as a new graduate student at UCLA in the early 2000s. The repeated conclusion in this literature was that people who knew a lot about national politics thought differently than those who had not attended to it much. To me, this sounded similar to the practice related effects that Raichle had been writing about and I suggested brain imaging as a potential tool for investigating political cognition. Though initially skeptical, Zaller later suggested that I could test at least my broad hypothesis using Donders' methodology with the first available American National Election Studies dataset to include response latency measures that came out in 1998. While the available data weakly supported the idea of quantifying cognitive differences between political novices and sophisticates using response latency ${ }^{10}$, a much richer dataset was generously provided by Robert Huckfeldt ${ }^{30}$ and this bolstered both the central theory and the potential for using fMRI.

Converse's ${ }^{1}$ claims that novices made political judgments with the cognitive equivalent of mental coin flips implied little intellectual effort and thus would suggest very short response times when using Donders' paradigm. It turned out, however, that people who did not know 
much about politics took dramatically longer to answer political questions than those who were knowledgeable ${ }^{31}$, consistent with the extensive literature on practice and rehearsal ${ }^{32}$. The result functioned as a proof of concept and was sufficient to get me in the door at UCLA's new Brain Mapping Division.

Traditional cognitive tasks dominated the initial work using functional brain imaging. For instance, early review pieces by Cabeza and Nyberg ${ }^{33,34}$ highlighted studies investigating attention, Stroop tasks, language processing, memory encoding and retrieval, and skill learning. Social cognition was nearly entirely absent. The view emerging out of this work would not have led one to believe that man was, by nature, a political animal-but rather that we were roughly similar to the lab rats and pigeons so frequently investigated!

\section{From cognitive neuroscience to social cognitive neuroscience}

Studies of racial perception and moral judgment were among the first social neuroimaging papers to gain attention. Elizabeth Phelps and colleagues ${ }^{35}$ found that activity in the amygdala correlated with measures of implicit racial bias. Alexandra Golby and colleagues ${ }^{36}$ showed that patterns of activity in memory and face-related regions of the brain mirrored difficulties that Whites had in recalling Black faces. And, Joshua Greene and colleagues ${ }^{37}$ showed that differences in how people judge two seemingly equivalent moral problems were reflected in differences in brain activity. Soon, enough work was coalescing around social observations and brain imaging to enable a new field of social cognitive neuroscience to emerge onto the scene as a fully-fledged entity ${ }^{38}$.

The first international Social Cognitive Neuroscience conference was held in 2001, bringing together a Tower of Babel like collection of senior academics from a range of disciplines who struggled for meaningful dialogue. A Google search for "social cognitive 
neuroscience" would yield 53 hits that year ${ }^{39}$. While that initial conference meeting was characterized by senior scholars from fields like primatology, economics, and neuroscience with vastly different disciplinary views of terms as basic as trust, it was just a few years later that New York Times columnist David Brooks ${ }^{39}$ described the meeting as "The Young and the Neuro." After receiving the nod from senior scholars, younger scholars had quickly converged on a common language and were, for example, running neuroscience studies of monkeys playing the behavioral economist's games, a dramatic example of E.O. Wilson's ${ }^{40}$ consilience as multiple fields converged on shared theories and methodologies. This consilience manifested in the foundation of the journals Social Cognitive and Affective Neuroscience and Social Neuroscience.

In these early days, the literature of neuroscience experiments broadly relevant to politics was extremely limited, which led to difficulty with experimental design and data analysis. My original fMRI studies, the first to combine functional brain imaging and political science were run in 2001. At the time, the work was conducted on a 3 Tesla (a household refrigerator magnet is 0.005 Tesla) MRI scanner that had been specially modified to enable functional imaging and the data analysis took a 64 processor supercomputer that filled an entire floor three days to converge. By the end of the decade, fMRI scanners were readily accessible at many universities around the world and that same data analysis could be run in three days on a consumer iMac.

Social cognitive neuroscience advanced rapidly, with noticeable differences in flavor and approach between American and European research ${ }^{41}$. Europeans developed work on theory of mind, mirror neurons, and empathy ${ }^{42}$. In contrast, American researchers tended to be more individually focused with studies of self-knowledge, emotion regulation, and implicit attitudes.

Soon enough groundwork had been laid for the journal Political Psychology to commission a special issue on the intersections of neuroscience and political science. From this 
early work through to the present, discussions of neuropolitics have focused on both promise and peril as repeated themes. While the measurement millennium prophesied by Converse in the opening quote had arrived, substantial and warranted criticism of fMRI's ability to measure subjective states persisted. As Marcus Raichle ${ }^{43}$ noted in a commentary to the special issue, the "tasks of interest are always associated with activity changes in large networks of brain areas with task-unique spatial and temporal properties.” Even in the best circumstances, converting data about task-related changes in brain activity into meaningful psychological insights, much less political processes, would continue to be a challenge.

\section{Neuropolitics: Initial findings}

The special issue of Political Psychology in 2003 staked out a number of central themes that continue to be at the heart of investigations in neuropolitics today. John Cacioppo and Penny Visser ${ }^{44}$ highlighted the difficulty in transcending many levels of analysis. Elizabeth Phelps and Laura Thomas ${ }^{45}$ cautioned against the tendency to view results from neuroimaging as somehow more definitive than traditional psychological methods. And Matthew Lieberman and colleagues ${ }^{46}$ illustrated how well-established theories of brain function have implications for political phenomena and sketched out how cognitive neuroscience could be used to both generate theories of political behavior and test those theories. As reviews and critiques of neuropolitics have appeared in the literature in the years since, these early words about the area's promises and perils continued to be echoed.

As neuropolitics transitioned from theoretical work to an experimental agenda, three themes in experimental design quickly emerged. One trend was exploring political attitudes with tasks where participants would report political attitudes in a manner roughly similar to the long tradition of answering survey questions in political science research. A second theme in research 
was for investigators to look for variations in neural activity as participants viewed faces. A third theme involved the study of mechanisms of basic cognition and perception to identify distinctions between liberals and conservatives.

My own dissertation reflected the first two tendencies with experiments asking participants to report their political attitudes and others asking them to view faces or visual scenes. The first experiment showed the effect of experience regarding national politics on the cognitive and neural mechanisms involved in political attitudes, in particular the brain's Default Mode Network ${ }^{47}$ (a network of brain regions that is highly active when a person is at rest). Drew Westen and colleagues ${ }^{48}$ likewise showed the same brain regions activated as politically knowledgeable participants answered political questions. Westen ${ }^{49}$ extrapolated from these findings in his well-received popular book, The Political Brain.

Kristine Knutson and colleagues ${ }^{50}$ investigated reactions to well known political faces using the Implicit Association Test and fMRI. Michael Spezio ${ }^{51}$ and his collaborators looked at how we could use fMRI to understand the role of negative attributions towards losing candidates and the pattern of neural activation that corresponds with those negative perceptions. Jonas Kaplan et al. ${ }^{52}$ also studied reactions to political faces, finding activity in regions often engaged in cognitive control when participants viewed candidates from the opposing party.

However, the first significant controversy arose soon after as some of the same team members described results from an fMRI study they had performed using faces of candidates in the upcoming presidential race in a New York Times Op-Ed ${ }^{53}$. An immediate response signed by a number of prominent cognitive neuroscientists and psychologists criticized the inferences being made from the data and its lack of peer review ${ }^{54}$. As I discuss below, it might possible to 
infer the subjective mental states of individuals as they react to political candidates, but doing so requires a complex set of conditions that were not met in the research described in the Op-Ed.

While reactions to political questions or the faces of political candidates have prompted a number of interesting neuropolitics studies, some of the most fascinating findings have emerged when nonpolitical tasks have been used to differentiate individuals on opposite sides of the political spectrum. Though political scientists have a long tradition of measuring responses to political stimuli based on information processing paradigms of political decision-making ${ }^{1,18,29,55}$, looking for fundamental differences in how the brain processes the world was motivated by theoretical insights coming from psychology and cognitive neuroscience ${ }^{46}$. David Amodio and colleagues ${ }^{56}$ found differences in how the brains of liberals and conservatives reacted to a version of the Go/No-Go task.

My colleagues and I ${ }^{57}$ were able to accurately differentiate liberals and conservatives using brain activity in response to a gambling task, even though the observable gambling behavior was identical. A series of studies coming from the University of Nebraska's political science label likewise demonstrated first that there were physiological differences in reactions to disgusting stimuli ${ }^{58}$ and later that the differences in brain reactivity were large enough that ideology could be correctly classified based on brain data after a single disgusting image ${ }^{59}$. Academy Award-winning actor Colin Firth was a coauthor on one of the studies in this vein after commissioning research on the political brain. Their work showed that liberals and conservatives could be reliably identified by differences in the size of brain regions implicated in the other studies ${ }^{60}$.

The converging results in even these first few neuropolitics papers are noteworthy, but perhaps not surprising. Regions in the Default Mode Network reliably appeared throughout the 
first studies in social cognitive neuroscience as individuals performed tasks involving the contemplation of themselves or their roles in social dynamics ${ }^{61}$. And, regions like the amygdala, basal ganglia, and insula were investigated precisely because they had been implicated in a range of decision-making tasks that researchers believed might be relevant to political cognition ${ }^{62}$. Nonetheless, it was heartening to see coherent threads emerging as the low hanging fruit was sampled from the tree of neuropolitics knowledge.

\section{Neuropolitics and its neighbors}

Though the first wave of neuropolitics research produced consistent findings, this line of inquiry has not led to the intensity of publications seen in the intersection of neuroscience with neighboring disciplines. Neuroeconomics has produced hundreds of papers in top journals and an entire academic society (the Society for Neuroeconomics) with annual meetings. Neurolaw has similarly generated a cottage industry of law review articles, books and textbooks, a number of conferences, and large funding commitments from the MacArthur Foundation ${ }^{63}$. So, why does neuropolitics appear to lag behind in development?

Lawyers and judges have had to deal with cases related to brain function since ancient times. Issues of mental capacity and intent can be seen as influencing legal reasoning back to the days of stone tablets and the Code of Hammurabi. As cognitive neuroscience provided new tools and insights, legal theorists immediately grasped the implications for both broader debates and specific cases. While more than a thousand neurolaw articles have been published exploring these implications ${ }^{63}$, only a rather small portion have actually involved experimental research see e.g. ${ }^{64}$. Thus, the nature of the discourse in neurolaw has centered on theory building, rather than theory testing. 
Neuroeconomics, in contrast, was able to connect quickly to the foundations laid by behavioral and experimental economics. Behavioral games like the dictator and ultimatum game fit nicely within the constraints of fMRI experimental design ${ }^{65}$. The same economic task can be performed repeatedly inside the scanner with variations in partners, incentives, or costs. While many of these games have clear implications for debates in political science ${ }^{66}$, political scientists and political psychologists often have been interested in experiments with a greater emphasis on naturalistic realism ${ }^{67}$ or connections to the current political context.

Because functional brain imaging typically relies on repeated measures of the same task condition, successful neuropolitics studies must involve stimuli that are realistic enough to be politically meaningful for the question at hand but also novel enough that each repeated instance of the task is engaging for the participant. Given severe constraints and significant variation among citizens in their knowledge of national politics ${ }^{68}$, experimental design is even more complicated when the requirements of functional imaging are added to the mix. As a consequence, many successful neuropolitics experiments have involved variations on tasks that have already been well tested in more traditional psychological contexts.

Neuroeconomics has also benefited from a convergence in research agendas. While many economists were questioning the axioms of rational choice theory, psychologists and cognitive neuroscientists were pushing their understanding of basic decision-making processes. Thus, the levels of analysis of primary concern to these researchers were relatively proximate. The interdisciplinary collaboration and funding necessary became routinized as coordinated efforts like the Society for Neuroeconomics expanded.

Political science and neuroscience have had a much smaller space of intersection. Questions at the heart of a lot of social cognitive neuroscience are adjacent to issues central to 
political science but the critical mass of crossover has yet to be achieved. Political science and political psychology have often focused on phenomena at a national or international scale, while much of social cognitive neuroscience has focused on dyadic or at most small group dynamics.

An interesting and productive counter example has been in racial attitudes. Some of the earliest work in social cognitive neuroscience focused on race ${ }^{35}$ with a sizeable literature emerging in its wake ${ }^{69}$ with exciting implications for political science. Racial attitudes have been an enticing area of inquiry for these approaches precisely because central concerns about implicit attitudes or pressures for social conformity converged with methodological strengths and theoretical foundations for understanding how automatic mental processes operated. The dynamic and highly contextual nature of racial attitudes ${ }^{70}$ along with the well-developed and creative experimental designs in this area suggest a ready source for inspiration that prospective researchers in neuropolitics should be investigating as we look for workable frameworks that can adapted for addressing central questions in political science.

Fortunately, as research in adjacent disciplines expands so does the potential for fruitful crossover with neuropolitics. As a recent review by Sekoul Krastev and colleagues ${ }^{71}$ notes, relatively few neuropolitics experiments have leveraged the reward paradigm that is at the center of much research in neuroeconomics. Economic theory's emphasis on individual utility and, in particular, on monetary payoffs, contrasts with political values that are often distal from the individual making the decision. Justice, equality, patriotism, and other central political values can heavily influence discourse and individual decision-making, and it is an open question whether expressions of these values rely on the same neural foundations found in neuroeconomics. As the points of contact with other related fields increase, new developments in 
methodologies and research paradigms will enhance the potential for cross-pollinated research in neuropolitics.

While neuropolitics has not yet had the influence seen in related disciplines, the potential identified early ${ }^{72}$ remains intact. Insights have been gained in our understanding of prejudice, motivated reasoning, attitudes, and ideology ${ }^{2,73}$. Early speculation on the distinct roles of automatic and controlled processing in political cognition ${ }^{46}$ have been borne out as research has advanced ${ }^{74}$. Moreover, promising leads about the interplay of policy goals and political identity are emerging ${ }^{75}$.

While discussions about the intersections between biology and politics have been controversial historically, mindsets have begun to shift. Findings about the biological heritability of political attitudes that were largely ignored in an earlier era ${ }^{22}$, have become some of the most cited works ${ }^{76}$ in contemporary political science decades later. A number of researchers have investigated evolutionary roots of political behavior ${ }^{77,78}$. And while no academic society devoted solely to neuropolitics has emerged, this work can far more easily find outlets in a variety of professional associations, divisions, interest groups, and scholarly journals that cater to work at the intersection of biology and politics more broadly ${ }^{79}$. Thus, while few political scientists would believe that their field is really a subdiscipline within biology ${ }^{80}$, many are far more open to the potential value for understanding biology and the brain in the context of politics than was previously the case.

\section{The future of neuropolitics}

Though fMRI has enabled an explosion in research in cognitive neuroscience and related disciplines over the years, it has some rather severe limitations, especially in relation to neuropolitics. For one, equipment costs run into the millions of dollars and require a significant 
staff with technical expertise to maintain the delicate apparatus and run the machine. Participants in fMRI experiments must lie very still at the center of a large super-conducting magnet. As a consequence, the possibilities for the actual social interactions that underpin politics are severely constrained and the types of stimuli and tasks that may be used are quite limited. The result is an experimental set-up far from the naturalistic environments that can boost external validity in political psychology research ${ }^{67}$. Additionally, while fMRI filled the methodological gap identified in the late 1980s, it is still restricted in terms of temporal resolution and causal inference due to fundamental characteristics of the method. The sibling disciplines to neuropolitics are taking advantage of alternative approaches to fMRI in order to sidestep its limitations and neuropolitics will need to follow suit as it develops.

\section{EEG}

One solution to the temporal resolution problem is the use of EEG. With this technique, millisecond resolution is attainable, rather than being stuck with the one-second resolution of fMRI. The traditional limitation of EEG techniques has been the difficulties with localization of the signal source within the brain, since EEG measures electrical activity along the surface of the scalp. However, the development of high-density event related potential (ERP) techniques means that a set of 128 (or more) electrodes along the scalp can provide data which enables inferences about the activity of even deep brain structures like the amygdala as it responds within 100 millisecsonds after a social stimulus ${ }^{81,82}$. This temporal resolution is valuable since it facilitates inference about the sequence of neural activity and thus causal structure of mental functions. Moreover, because the data is gathered via a hairnet-like device rather than in the center of a giant magnet, the participant is able to experience a far more natural range of interactions and stimuli. 


\section{fNIRS}

Like the high-density ERP approach, functional Near Infrared Spectroscopy (fNIRS) uses a hairnet of sensors situated on the scalp. However, rather than measuring electrical activity, fNIRS uses laser diodes and photodiode detectors to send photons of light through the head and detect changes in the passage of those photons. The most commonly used variant is continuous wave $(\mathrm{CW})$, which detects shifts in blood flow that correspond with underlying neural activity, in a manner similar to fMRI. Not surprisingly, fMRI and fNIRS produce equivalent results across a range of cognitive tasks ${ }^{83}$. Connected to the same shifts in metabolism and blood flow, the two approaches share many of the same limitations. For instance, though very quick fluctuations in light can be detected in fNIRS, the practical temporal resolution is constrained to the slow shifts over seconds as the blood oxygenation levels change to support neural activity. But, fNIRS is significantly cheaper than fMRI, can be used in more naturalistic settings, is dramatically quieter, and less susceptible to motion artifacts than either fMRI or EEG/ERP measures ${ }^{84}$.

One significant limitation to fNIRS is that the technique can only directly detect changes in blood oxygenation at a depth of 2 to $3 \mathrm{~cm}$. So while much of the outer cortex can be studied, activity in deep brain structures such as the amygdala are not directly observable. Nonetheless, given the brain's connectivity, some evidence demonstrates the possibility of inferring deep brain activity from measurable changes in the outer cortex ${ }^{85}$.

\section{EROS}

Event related optical signal, or EROS ${ }^{86}$, relies on changes in optical scattering that occur when neural tissue is active. Because the technique focuses specifically on neural activity, rather than relatively slow changes in blood flow correlated with neural activity, the approach allows for temporal resolution below 100 milliseconds and is much closer to the source at interest. 
While EROS provides a more direct measure of neural activity, it cannot provide insight into neural structure. Thus, to ensure accurate understanding of the neuroanatomy involved in the task, this approach typically relies on structural MRI in addition to optical imaging. This dual approach to data collection naturally limits utilization due to equipment costs and the effort involved in collecting data from two sources. Additionally, significant concerns have been raised about how consistently findings using the EROS approach can be replicated ${ }^{87,88}$.

\section{Investigating disruptions in brain activity}

While a variety of imaging methods all seek to make inferences about mental function by looking at brain activity, another approach is to investigate disruptions of activity. The famous case of Phineas Gage ${ }^{89}$, who suffered trauma to the left frontal lobe and experienced significant personality changes, and the aphasic patients of Paul Broca ${ }^{26}$, who suffered damage to the region named after him, provided foundational insights into cognitive processes through disorders in brain function. In my dissertation ${ }^{47}$, I proposed using patients suffering from anterograde amnesia to test hypotheses from Milton Lodge and others ${ }^{90}$ regarding "online" impressions of candidates. Jason Coronel and colleagues ${ }^{91}$ later carried out this research out as part of his dissertation $^{92}$, showing that amnesic patients who are unable to recall previous information about the political issue positions of candidates can nonetheless have their attitudes about the candidates altered by the same information they cannot recall having seen.

Just as they have been vital for neuroscience since its earliest days, patient populations can provide powerful opportunities for future neuropolitics research. The tragedy of braininjured Vietnam veterans has led to decades of important insights, with studies of veterans who sustained damage to their prefrontal cortex adding to prior work. Findings have provided important insights concerning theory of mind, goal directed social behavior, moral judgment, 
emotional intelligence, stereotypes, and a wide range of social cognition ${ }^{93}$. Since the development of the Vietnam head injury study, a number of projects have gathered brain injury patients and benefited from their participation in a wide range of studies. Researchers in neuropolitics should benefit from collaborations with neurologists and neuropsychiatrists who work with patient populations and are interested in understanding the political implications of brain injury ${ }^{73,94}$.

Beyond brain injury, a wide range of patient populations can yield insights for questions at the heart of political science. Individuals with borderline personality disorder (BPD), for instance, have a stronger tendency to idealize or devalue. As a consequence, such individuals then have a more difficult time restoring reciprocity in an iterated trust game ${ }^{95}$, have stronger reactivity in $\mathrm{mPFC}$ to experiencing social exclusion ${ }^{96}$, and possess stronger negative stereotypes regarding social outgroups ${ }^{97}$. With half of all Americans experiencing an episode of mental illness during their lifetime ${ }^{98}$, understanding the implications for political attitudes and political behaviors is critical. By investigating the particular ways that specific disorders alter our political psychology we can enhance our understanding of the mental and emotional processes that underlie our political world. Additionally, benefits can obtain for the patient populations, as the iterated trust game appeared strongly diagnostic for BPD, a notoriously difficult condition to diagnose ${ }^{95}$.

Transcranial Magnetic Stimulation (TMS) is a technique that can temporarily disrupt the function of a specific brain region through the introduction of a focused magnetic field. In this way, TMS mimics the effect of a lesion, but only for a short time and without lasting effects. The approach is particularly useful for testing hypotheses about the specific contribution of a brain region to a broader mental process. For instance, Liane Young and colleagues ${ }^{99}$ used TMS to 
disrupt the right temporoparietal junction (RTJP) in order to show that undermining the function of that area also impaired participants' ability to take account of mental states when making moral judgments. Though RTJP had been implicated previously in functional imaging studies looking at our ability to infer the mental states of others, showing that disruptions to the region also impairs that ability strengthens the case. As with other types of lesion studies, TMS enables a much stronger set of inferences about causation than is typically available with functional imaging approaches. However, TMS is limited to the regions of the brain closest to the scalp, thus deeper brain areas are inaccessible.

An alternative to TMS is transcranial direct current stimulation (tDCS) which uses a relatively simple device to create weak electrical currents that modifies neural excitability and activity ${ }^{100}$. The method has a lot in common with TMS in terms of both potential and limitations. However, the technology is much simpler and inexpensive, and thus it can be used affordably on multiple participants at the same time. For example, in one study researchers were able to use tDCS simultaneously on six participants who were playing ultimatum games with a series of 12 partners ${ }^{101}$. Compared with a placebo condition, those who had their right dorsolateral prefrontal cortex activity disrupted by tDCS were more likely to accept unfair offers. Note that some researchers have questioned the replicability of tDCS as a measure, however ${ }^{102}$.

One important limit common to both TMS and tDCS is that deep brain structures are out of reach. However, a new technique looks to transcend this problem, without the need for neurosurgery. By applying a high-frequency oscillating electrical field at multiple locations on the scalp it is possible to drive activity in deep neural tissue without disrupting cortical structures. Though currently only demonstrated with a mouse model, researchers expect to apply it to humans ${ }^{103}$. As a consequence, neural activity in the amygdala or hippocampus could soon 
be altered temporarily in neuropolitical studies to help isolate the role of these deep structures in a variety of political experiences, processes, and behaviors.

Moving forward, neuropolitics will also want to take advantage of developmental approaches to political psychology. Though historically important work has been done on the development of political attitudes and behaviors in children ${ }^{104,105}$, this area of inquiry has been significantly undervalued in political science in recent years ${ }^{106}$, especially compared with the broader work in contemporary developmental psychology ${ }^{107}$ and developmental social neuroscience ${ }^{108}$. For instance, while the biological heritability of political attitudes is quite stable across the adult lifespan, early political attitudes are entirely dominated by the effects of socialization ${ }^{109}$. The evidence from genopolitics then leads to contradictory expectations about what might occurring in the development of childrens' political brains.

Another important direction for the future will involve combinations of the previously described approaches. Francesca Happé and Uta Frith ${ }^{110}$ have argued for deeper theorizing about atypical social cognition from a developmental neuroscience view. For example, the fact that racial stereotyping, but not gender stereotyping, is impaired in children with Williams syndrome ${ }^{111}$ provides further confirmation of an evolutionary psychology account of the origins of racial discrimination as built on mechanisms for coalitional cognition ${ }^{112}-$ which are impaired in Williams patients.

Because of the lower costs of some of the methods mentioned, it is also possible to use them simultaneously and with multiple participants. Simultaneous imaging of multiple participants is known as hyperscanning and when combined with the freedom associated with running subjects outside of an fMRI scanner, it can lead to far more naturalistic experiments. In a study of social ranking behaviors, pairs of participants were examined using fNIRS, EEG/ERP, 
and response times ${ }^{113}$, enabling multiple measures of mental processes. Other studies have used functional imaging approaches with both neurotypical and clinical populations (like BPD) to understand how patients with these conditions compare with typical individuals in a range of social cognition tasks ${ }^{95,96}$. As neuropolitics research develops and becomes more sophisticated, presenting converging lines of evidence across methodologies will be critical for fostering confidence that findings are not mere artifacts of the experimental procedure or lab situation.

Finally, while fMRI devices with a magnetic field strength of 3 Tesla are now relatively common, more powerful machines have come on the scene in recent years. Ultra high field devices, such as 7 Tesla fMRI scanners, are still relatively new but initial studies have demonstrated benefits relevant to the future of neuropolitics. In particular, regions like the amygdala have been difficult to image given the spatial resolution of typical 3T fMRI studies and other constraints, but with 7T fMRI significantly smaller voxels (the the 3D version of pixels) can be, enabling far greater precision given the spatial and temporal tradeoffs ${ }^{114}$. The greater precision and sensitivity of 7T has led to an increasing number of research centers using these devices. However, the time needed to acquire each slice means that imaging the whole brain can provide a challenge ${ }^{115}$ and additional artifacts from the imaging process must be managed ${ }^{116}$. As researchers continue to develop proficiency with the nuances of $7 \mathrm{~T}$ imaging, many of the hurdles are being overcome and the new approach is yielding promising results ${ }^{117}$.

\section{Conceptualizing experiments: ROI and whole brain analysis}

While the new measurement tools bode well for a future of neuropolitics research where the costs are much lower and the experimental conditions far more naturalistic, an important fundamental shift is coming in terms of new ways of conceptualizing experiments. Two particular advances involve the use of machine learning for data analysis and the paradigm of 
neuroforecasting. Even while utilizing familiar equipment, these techniques provide qualitatively different ways of viewing the enterprise of neuropolitics.

The traditional approach to brain imaging focuses on two strategies for data analysis. The first, region of interest (ROI) analysis, hypothesizes that a specific brain region is involved in the cognitive task of interest and tests that hypothesis by extracting data from that region to compare activity in task and control conditions. This approach derives from the localization hypothesis that is at the core of much neuroscience work, namely, that there are discrete regions of the brain that are engaged in specific mental activities. By measuring the activity in a particular region, we can then infer the engagement of a specific mental process. The ROI approach is most powerful when used in a context where there are strong reasons to believe that a particular region is involved in a particular cognitive task. One problem is that researchers are often unclear which mental tasks or brain regions might be involved in the phenomena of interest. By limiting investigation to a specific region, one might miss critically important activity in other areas.

This limitation can be circumvented by a second approach, referred to as whole brain analysis. In both ROI and whole brain analysis, data might be collected for the entire brain at once; the difference is in the analysis of the data collected. With whole brain analysis, the strategy is to run statistical comparisons for each of the brains' thousands of voxels, then correct for many simultaneous analyses, and set a statistical threshold for the reliability of the clusters of activity that result. In this way, researchers can discover unexpected engagement with the task regardless of where in the brain it occurs. One downside is that this type of analysis often leads to "see what lights up" experimental designs that are driven by overly vague theory that "the brain is probably doing something different when you do this task of interest than when you do 
not." The resulting activity might then be subject to post-hoc interpretations that get reframed in writing up the hypothesis test.

In some cases, an ROI analysis is carried out after the whole brain analysis in a manner that can trigger inference problems, and in particular puzzlingly high correlations, similar to the issue of selecting on the dependent variable (choosing cases based on a criteria and then using the cases as evidence of the criteria) familiar in political science ${ }^{118}$. While some papers are overzealous in their analyses of unexpected results from whole brain analyses, there can also be a problem of sweeping a puzzling finding under the rug or sticking it in supplemental materials without further mention see discussion in ${ }^{70}$.

A more fundamental issue arises from the conceptual framework of localization. While there is considerable evidence of the connection between particular brain regions and specific mental processes, the brain is also extremely interconnected and mental processes are often distributed. Thus, looking at one voxel, one anatomical region, or one activation cluster can give a false impression of how much, and what parts, of the brain exactly are engaged during the processing of a task. Rather than focusing on specific regions, clusters, or networks within the brain, machine-learning approaches often leverage all of the data from a whole brain scan in order to model the phenomena of interest.

\section{Machine learning approaches}

Typical fMRI analysis relies on the familiar logic of regression, using a General Linear Model based on the experimental parameters to predict the time series of data in a particular voxel. Typical machine learning approaches reverse this logic, predicting the experimental parameters based on the activity in many voxels ${ }^{119}$. In this alternative view, fMRI data analysis is considered to be a pattern classification problem - is the pattern of brain activity associated 
with one mental function or another ${ }^{120}$ ? After training the classifier with an example set of data, researchers can see how well the classifier is able to correctly classify the testing set. This alternative view of the data analytic process also opens up new research paradigms for exploration.

Neuropolitics researchers have used machine-learning algorithms to classify individuals as liberal or conservative based upon brain structure or function ${ }^{59,60}$. One study was able to correctly classify a person as liberal or conservative with about 85 percent accuracy based on a single disgusting stimulus (Ahn et al., 2014). However, the machine learning approach allows for even more provocative applications such as "mind-reading" (inferring perceptual, emotional, and cognitive states from brain imaging data) and "neuroforecasting" (inferring the future behavior of individuals or mass populations from brain activity in small groups of individuals).

The conventional use of fMRI data has been in forward inference, where the data resulting from an fMRI experiment is used to distinguish between two competing theories about the engagement of neural mechanisms ${ }^{121}$. Attempts to use fMRI for reverse inference, making claims about mental processes based upon activity in specific brain regions for instance, have been far more problematic ${ }^{122}$-especially in the context of neuropolitics ${ }^{123}$. One challenge is that this use of data suffers from a fallacy akin to affirming the consequent. Thus, while a series of studies have shown that size or engagement of the amygdala is correlated with conservatism (forward inference), it remains unclear what mental function or trait (threat, fear, anxiety, social cognition, etc.) is driving the observed differences (reverse inference).

The use of machine-learning approaches, however, has strengthened the ability to make inferences from fMRI data. After training, a classifier algorithm can be used to distinguish which mental task an individual is performing. For instance, after tuning an algorithm to a training set 
of data containing photos of different objects (e.g., faces, houses, cats, shoes, chairs, and so on), the algorithm can then be used to identify when a person is viewing a cat ${ }^{124}$. Beyond mere "mind reading" of object category perception, however, is the capacity to successfully interpret a range of more nuanced brain activity ${ }^{120}$, such as the identification of specific stimuli based on fMRI data (e.g., knowing whether a person is thinking about a specific dog, rather than the general category of dogs) ${ }^{125}$ or the semantic content of natural movies (e.g,. Were you watching a man walking or a school of fish swimming?) ${ }^{126}$. While earlier research often led to extensive caveats about our ability to infer mental states, emotions, or perceptions based on brain activity, many of those caveats have fallen to the continued progress in methodology.

\section{Neuroforecasting}

Elliot Berkman and Emily Falk ${ }^{127}$ have argued for another new theoretical direction for the analysis of fMRI data which neuropolitics will benefit from. Both the traditional forward inference from fMRI and the more problematic reverse inference approaches have focused upon the connection between psychological processes and neural mechanisms. Political science, however, has often been more concerned about real world behaviors, and shunned inquiry into the mental events behind them. Berkman, Falk, and others have demonstrated the potential for the prediction of these real world outcomes directly from brain imaging data.

While mind reading from an individual highlights a number of surprising ethical problems that neuropolitics will need to address, developing work in neuroforecasting suggests it is possible to not only predict the future behavior of individuals but to predict the behaviors of large numbers of people based upon brain activity in a much smaller group. One of first studies in this direction predicted the use of sunscreen days after participants had been brain imaged while viewing material encouraging skin protection ${ }^{128}$. Later it was shown that smoking 
reduction could be predicted a month later by brain activity while participants watched antismoking messages ${ }^{129}$. In both cases, the predictions of future behaviors were improved with the fMRI data beyond self-report measures, consistent with a large body of literature regarding the function of both our consciously accessible and automatic mental processes ${ }^{130,131}$. When brain imaging and self-report data are combined, behaviors in the future can sometimes be accurately forecast.

The next step in this line of research has investigated whether the real world behaviors of large numbers of people can be predicted based on a smaller set of test groups. One study, again focusing on smokers, examined neural responses to a series of smoking cessation ads and found that the likelihood of members of the general public calling 1-800-QUIT NOW after each of the test ads could be predicted by the brain activity of the smaller group ${ }^{132}$. Another study, in neuroeconomics, used brain activity within a small number of people who responded to realworld requests for microloans to successfully predict whether those requests would be successful at the level of the real market ${ }^{133}$.

While traditional focus group approaches have long been used in advertising and can account for as much as half the variance in population-level responsiveness to ads, retail entrepreneur John Wanamaker's complaint a century ago that an unknown half of all advertising is wasted still remains true. However, one neuromarketing comparison of traditional focus group self report data with a range of indirect measurement techniques, including Implicit Association Tests, eye tracking, EEG, biometrics, and fMRI, showed that only fMRI data could dramatically improve on the insights gained from self report. Researchers were able to account for 85.6 percent of the variation in responsiveness to ads run by a six large corporations in real world market conditions, a 59.4 percent improvement over the use of self report alone ${ }^{134}$. 


\section{Discussion}

The use of neuroscientific methods to ascertain the political attitudes and behaviors of individuals and large portions of the population, however, should give us pause. For one, the broader implications of these rapidly materializing techniques need to be developed. Ideological purity has often demanded by both authoritarians and (on occasion) democracies attempting to root out perceived enemies from within. How would the purges of Joseph Stalin, Mao Tse-tung, or even Joseph McCarthy have differed if they had the tools of neuropolitics at hand? Will the selections of party nominees or Supreme Court justices someday be influenced by brain scans? As distasteful as these possibilities may sound, how long will it take until the neuromarketing techniques that are currently influencing other sectors of society come into full play in the political domain? Trends would indicate not that long.

Already, some are engaged in practical neuropolitics, but the ethical implications and the threats to democratic deliberation are woefully underappreciated-and under-theorized. Days after a recent New York Times article highlighted the use of neuropolitics methods to sway a Mexican political campaign ${ }^{135}$, the governing party vowed to stop using the approach ${ }^{136}$. The founder of one of the firms involved claimed, "We cannot read minds and of course we cannot change them." However, the developing work in neuropolitics suggests that these aims are increasingly within reach. The reporting intimates that campaigns around the world have already started using these tools, including for presidential elections in the U.S.

Neuropolitics, a field studying the most complex thing known to humans that likely evolved due to the demands created by exactly the context we want to understand it operating in, is still in its infancy ${ }^{4}$. An analogy from biology illuminates where the field currently stands. The C. elegans worm is a model species with 302 neurons in its tiny brain that have been laboriously 
mapped out ${ }^{137}$. But even then, we are far from being able to fully understand the function of this worm's brain, much less the role its brain plays in its very simple social life ${ }^{138}$. The human brain, in contrast, has around eighty-six billion neurons and a hundred trillion synapses. It is the result of a three million year cognitive arms race within the species to compete for survival while paying the ever increasing metabolic costs to feed this device that converts glucose into love and hate, poetry and war. As our understanding of the brain is developing, old notions that our brains are somehow hardwired are giving way to a realization that they are wired to be flexible precisely because of the pressures of being a political animal. In the long run, the field has the potential to fundamentally change the way we understand human nature. But we are just taking the first steps in that journey. 


\section{References}

1. Converse P. The Nature of Belief Systems in Mass Publics. In: Apter D, ed. Ideology and Discontent. New York: Free Press; 1964:206-61.

2. Jost JT, Nam HH, Amodio DM, Van Bavel JJ. Political Neuroscience: The Beginning of a Beautiful Friendship. Political Psychology 2014;35:3-42.

3. Fowler JH, Schreiber D. Biology, politics, and the emerging science of human nature. Science 2008;322:912-4.

4. Schreiber D. Political cognition as social cognition: Are we all political sophisticates? In: Crigler A, MacKuen M, Marcus GE, Neuman WR, eds. The Affect Effect: Dynamics of Emotion in Political Thinking and Behavior. Chicago: University of Chicago; 2007:48-70.

5. Aristotle. Aristotle : the Politics and the Constitution of Athens. Rev. student ed.

Cambridge ; New York: Cambridge University Press; 1996 [350 B.C.].

6. Masters RD. The nature of politics. New Haven: Yale University Press; 1989.

7. de Waal FBM. Chimpanzee politics : power and sex among apes. Rev. ed. Baltimore:

Johns Hopkins University Press; 1998.

8. Holekamp KE, Sakai ST, Lundrigan BL. The spotted hyena (Crocuta crocuta) as a model system for study of the evolution of intelligence. Journal of Mammalogy 2007;88:545-54.

9. Connor RCR, Watson-Capps JJJ, Sherwin WBW, Krützen MM. A new level of complexity in the male alliance networks of Indian Ocean bottlenose dolphins (Tursiops sp.). Biology Letters 2011;7:623-6.

10. Schreiber D. Thinking About Politics. 1998.

11. Aristotle. Aristotle's On the soul (De anima). Grinnell, Iowa: Peripatetic Press; 1981 (original 350 B.C.E).

12. Descartes R. Meditations on first philosophy : in which the existence of God and the distinction of the soul from the body are demonstrated. Indianapolis: Hackett Pub. Co.; 1979 (original work 1641).

13. Locke J. An essay concerning humane understanding : in four books. George Fabyan Collection (Library of Congress) ed. London: Printed by Eliz. Holt for Thomas Bassett ... 1690.

14. Pinker S. The blank slate : the modern denial of human nature. New York: Viking; 2002.

15. Zimmer C. Soul made flesh : the discovery of the brain - and how it changed the world. London: Heinemann; 2004.

16. Freud S. Zur Auffassung der Aphasien : eine kritische Studie. Leipzig: F. Deuticke; 1891.

17. Skinner BF. The behavior of organisms; an experimental analysis. New York, London: D. Appleton-Century Company, incorporated; 1938.

18. Campbell A, Converse PE, Miller WE, Stokes DE. The American voter. New York: Wiley; 1960.

19. Downs A. An Economic Theory of Democracy. New York: HarperCollins Publishers, Inc.; 1957.

20. Jackson JP, Weidman NM. Race, racism, and science : social impact and interaction. New Brunswick, N.J.: Rutgers University Press; 2006.

21. Wahlke JC, Lodge MG. Psychophysciological Measures of Political Attitudes and Behavior. Midwest Journal of Political Science 1972;16:505-37.

22. Eaves LJ, Eysenck HJ. Genetics and the development of social attitudes. Nature 1974;249:288-9. 
23. Sperry RW, Zaidel E, Zaidel D. Self recognition and social awareness in the disconnected minor hemisphere. Neuropsychologia 1979;17:153-66.

24. Churchland PS, Sejnowski TJ. Perspectives on cognitive neuroscience. Science 1988;242:741-5.

25. Bandettini PA. Functional MRI: A confluence of fortunate circumstances. NeuroImage 2012.

26. Broca PM. [The discovery of cerebral localization]. Rev Prat 1999 (Original work 1861);49:1725-7.

27. Raichle ME. Visualizing the mind. Scientific American 1994;270:58-64.

28. Donders FC. On the Speed of Mental Processes. In: Koster WGEdaT, ed. Attention and Performance. Amsterdam: North Holland; 1969 (original work 1868-1869):412-31.

29. Zaller JR. The Nature and Origin of Mass Opinion. New York: Cambridge University Press; 1992.

30. Huckfeldt R, Levine J, Morgan W, Sprague J. Accessibility and Political Utility of Partisan and Ideological Orientations. American Journal of Political Science 1999;43:888-911.

31. Schreiber D. Looking into Their Minds: Latency in Survey Response as Determined by Political Sophistication, Issue Publics, and Cognitive Conflict. Annual Meeting of the Midwest Political Science Association; 2000; Chicago.

32. Palmeri TJ. Theories of automaticity and the power law of practice. Journal of Experimental Psychology: Learning, Memory, \& Cognition 1999;25:543-51.

33. Cabeza R, Nyberg L. Imaging cognition II: An empirical review of 275 PET and fMRI studies. J Cogn Neurosci 2000;12:1-47.

34. Cabeza R, Nyberg L. Imaging Cognition: An Empirical Review of PET Studies with Normal Subject. Journal of Cognitive Neuroscience 1997;9:1-26.

35. Phelps EA, O'Connor KJ, Cunningham W, et al. Perfomance on Indirect Measures of Race Evaluation Predicts Amygdala Activation. Journal of Cognitive Neuroscience 2000;12:72938.

36. Golby AJ, Gabrieli JDE, Chiao JY, Eberhardt JL. Differntial Responses in the Fusiform Region to Same-Race and Other-Race Faces. Nature 2001;4:845-50.

37. Greene JD, Sommerville RB, Nystrom LE, Darley JM, Cohen JD. An fMRI investigation of emotional engagement in moral judgment. Science 2001;293:2105-8.

38. Ochsner KN, Lieberman MD. The emergence of social cognitive neuroscience. American Psychologist 2001;56:717-34.

39. Brooks D. The Young and the Neuro. New York Times 2009 October 12, 2009.

40. Wilson EO. Consilience: The unity of knowledge. Polit Life Sci 1999;18:341-.

41. Lieberman MD. A geographical history of social cognitive neuroscience. NeuroImage 2012;61:432-6.

42. Singer T. The past, present and future of social neuroscience: a European perspective. NeuroImage 2012;61:437-49.

43. Raichle ME. Social Neuroscience: A Role for Brain Imaging. Political Psychology 2003;24:759-64.

44. Cacioppo JT, Visser PS. Political Psychology and Social Neuroscience: Strange Bedfellows or Comrades in Arms? Political Psychology 2003;24:647-56.

45. Phelps EA, Thomas L. Race, Behavior, and the Brain: The Role of Neuroimaging in Understanding Complex Social Behaviors. Political Psychology 2003;24:747-58. 
46. Lieberman M, Schreiber D, Ochsner K. Is Political Cognition Like Learning to Ride a Bicycle? How Cognitive Neuroscience Can Inform Research on Political Thinking. Political Psychology 2003;24:681-704.

47. Schreiber D. Evaluating Politics: A Search for the Neural Substrates of Political Thought [Dissertation]. Los Angeles: UCLA; 2005.

48. Westen D, Blagov P, Harenski K, Kilts C, Hamann S. Neural Bases of Motivated

Reasoning: An fMRI Study of Emotional Constraints on Partisan Political Judgment in the 2004 U.S. Presidential Election. Journal of Cognitive Neuroscience 2006;18:1947-58.

49. Westen D. The political brain : the role of emotion in deciding the fate of the nation. New York: PublicAffairs; 2007.

50. Knutson KM, Wood JN, Spampinato MV, Grafman J. Politics on the brain: an FMRI investigation. Social neuroscience 2006;1:25-40.

51. Spezio ML, Rangel A, Alvarez RM, et al. A neural basis for the effect of candidate appearance on election outcomes. Soc Cogn Affect Neur 2008;3:344-52.

52. Kaplan JT, Freedman J, Iacoboni M. Us versus them: Political attitudes and party affiliation influence neural response to faces of presidential candidates. Neuropsychologia 2007;45:55-64.

53. Iacoboni M, Freedman J, Kaplan J, et al. This Is Your Brain on Politics. New York Times2007:414.

54. Aron AR, Badre D, Brett M, et al. Politics and the Brain - The New York Times. New York Times2007.

55. Axelrod R. Schema Theory: An Information Processing Model of Perception and Cognition. American Political Science Review 1973;67:1248-66.

56. Amodio DM, Jost JT, Master SL, Yee CM. Neurocognitive correlates of liberalism and conservatism. Nat Neurosci 2007;10:1246-7.

57. Schreiber D, Fonzo G, Simmons AN, et al. Red Brain, Blue Brain: Evaluative Processes Differ in Democrats and Republicans. PLoS ONE 2013;8:e52970.

58. Oxley DR, Smith KB, Alford JR, et al. Political attitudes vary with physiological traits. Science 2008;321:1667-70.

59. Ahn WY, Kishida KT, Gu X, et al. Nonpolitical Images Evoke Neural Predictors of Political Ideology. Current Biology 2014;24.

60. Kanai R, Feilden T, Firth C, Rees G. Political Orientations Are Correlated with Brain Structure in Young Adults. Current biology 2011;21:677-80.

61. Lieberman MD. Social : Why Our Brains Are Wired to Connect2013.

62. Spezio M, Adolphs R. Politics and the Evolving Neuroscience Literature. In: Crigler A, MacKuen M, Marcus GE, Neuman WR, eds. The Affect Effect : Dynamics of Emotion in Political Thinking and Behavior. Chicago: University of Chicago Press; 2007:71-95.

63. Jones OD, Marois R, Farah MJ, Greely HT. Law and Neuroscience. Journal of Neuroscience 2013;33:17624-30.

64. Aharoni E, Vincent GM, Harenski CL, et al. Neuroprediction of future rearrest. P Natl Acad Sci 2013.

65. Krueger F, Grafman J, McCabe K. Neural correlates of economic game playing. Philos T Roy Soc B 2008;363:3859-74.

66. Dawes CT, Loewen PJ, Schreiber D, et al. Neural basis of egalitarian behavior.

Proceedings of the National Academy Of Sciences 2012;109:6479-83. 
67. Ansolabehere S, Iyengar S. Going negative : how attack ads shrink and polarize the electorate. New York: Free Press; 1995.

68. Delli Carpini MX, Keeter S. What Americans Know About Politics and Why It Matters. New Haven: Yale University Press; 1996.

69. Amodio DM. The neuroscience of prejudice and stereotyping. Nature Reviews Neuroscience 2014.

70. Schreiber D, Iacoboni M. Huxtables on the Brain: An fMRI study of Race and Norm Violation. Political Psychology 2012;33:307-418.

71. Krastev S, McGuire JT, McNeney D, et al. Do Political and Economic Choices Rely on Common Neural Substrates? A Systematic Review of the Emerging Neuropolitics Literature. Front Psychol 2016;7:264.

72. Tingley D. Neurological imaging as evidence in political science: a review, critique, and guiding assessment. Social Science Information 2006;45:5.

73. Mendez MF. A Neurology of the Conservative-Liberal Dimension of Political Ideology. J Neuropsychiatry Clin Neurosci 2017;29:86-94.

74. Tusche A, Kahnt T, Wisniewski D, Haynes J-D. Automatic processing of political preferences in the human brain. NeuroImage 2013;72:174-82.

75. Jenke L, Huettel SA. Issues or Identity? Cognitive Foundations of Voter Choice. Trends Cogn Sci (Regul Ed) 2016;20:794-804.

76. Alford JR, Funk C, L., Hibbing JR. Are Political Orientations Genetically Transmitted? American Political Science Review 2005;99:153-67.

77. Hibbing JR, Smith KB, Alford JR. Predisposed : liberals, conservatives, and the biology of political differences. New York: Routledge; 2013.

78. Haase VG, Starling-Alves I, Universidade Federal de Minas Gerais B, Universidade Federal de Minas Gerais B, Universidade Federal de Minas Gerais B, Instituto Nacional de Ciência e Tecnologia: Comportamento CeE, Brazil. In search of the moral-psychological and neuroevolutionary basis of political partisanship. Dement neuropsychol 2017;11:15-23.

79. Peterson SA, Somit A. Handbook of biology and politics. Cheltenham, UK ; Northhampton, MA: Edward Elgar Publishing; 2017.

80. Rosenberg A. Why Social Science is Biological Science. J Gen Philos Sci in press:1-29.

81. Decety J, Cacioppo S. The speed of morality: a high-density electrical neuroimaging study. J Neurophysiol 2012;108:3068-72.

82. Yoder KJ, Decety J. Spatiotemporal neural dynamics of moral judgment: a high-density ERP study. Neuropsychologia 2014.

83. Cui X, Bray S, Bryant DM, Glover GH, Reiss AL. A quantitative comparison of NIRS and fMRI across multiple cognitive tasks. NeuroImage 2011;54:2808-21.

84. Gervain J, Mehler J, Werker JF, Nelson CA. Near-infrared spectroscopy: a report from the McDonnell infant methodology consortium. Developmental ... 2011.

85. Liu N, Cui X, Bryant DM, Glover GH, Reiss AL. Inferring deep-brain activity from cortical activity using functional near-infrared spectroscopy. Biomed Opt Express 2015;6:107489.

86. Gabriele Gratton MF. Fast Optical Imaging of Human Brain Function. Front Hum Neurosci 2010;4.

87. Radhakrishnan H, Vanduffel W, Deng HP, Ekstrom L. Fast optical signal not detected in awake behaving monkeys. NeuroImage 2009. 
88. Steinbrink J, Kempf FCD, Villringer A, Obrig H. The fast optical signal--robust or elusive when non-invasively measured in the human adult? NeuroImage 2005;26:996-1008.

89. Macmillan M. Restoring Phineas Gage: a 150th retrospective. J Hist Neurosci 2000;9:46-

66.

90. Lodge M, McGraw K, Stroh P. An impression-driven model of candidate evaluation. American Political Science Review 1989;83:499-19.

91. Coronel JC, Duff MC, Warren DE, et al. Remembering and Voting: Theory and Evidence from Amnesic Patients. American Journal of Political Science 2012;56:837-48.

92. Coronel J. Memory and voting: neuropsychological and electrophysiological investigations of voters remembering political events. Illinois: University of Illinois at UrbanaChampaign; 2012.

93. Raymont V, Salazar AM, Krueger F, Grafman J. "Studying injured minds" - the Vietnam head injury study and 40years of brain injury research. Front Neurol 2011;2:15.

94. Arciniegas DB, Anderson CA. Toward a Neuroscience of Politics. J Neuropsychiatry Clin Neurosci 2017;29:84-5.

95. King-Casas B, Sharp C, Lomax-Bream L, Lohrenz T, Fonagy P, Montague PR. The rupture and repair of cooperation in borderline personality disorder. Science 2008;321:806-10.

96. Ruocco AC, Medaglia JD, Tinker JR, Ayaz H. Medial prefrontal cortex hyperactivation during social exclusion in borderline personality disorder. Psychiatry Res 2010.

97. Dunbar E. The relationship of DSM personality disorder criteria and Gough's prejudice scale: Exploring the clinical manifestations of the prejudiced personality. Cultural Diversity and Mental Health 1997;3:247-58.

98. Kessler RC, Berglund P, Demler O, Jin R, Merikangas KR, Walters EE. Lifetime prevalence and age-of-onset distributions of DSM-IV disorders in the National Comorbidity Survey Replication. Arch Gen Psychiatry 2005;62:593-602.

99. Young L, Camprodon JA, Hauser M, Pascual-Leone A, Saxe R. Disruption of the right temporoparietal junction with transcranial magnetic stimulation reduces the role of beliefs in moral judgments. Proc Natl Acad Sci USA 2010.

100. Nitsche MA, Cohen LG, Wassermann EM, et al. Transcranial direct current stimulation: state of the art 2008. Brain stimulation 2008:206-23.

101. Knoch D, Nitsche MA, Fischbacher U, Eisenegger C, Pascual-Leone A, Fehr E. Studying the Neurobiology of Social Interaction with Transcranial Direct Current Stimulation--The Example of Punishing Unfairness. Cereb Cortex 2008;18:1987-90.

102. Horvath JC, Forte JD, Carter O. Quantitative Review Finds No Evidence of Cognitive Effects in Healthy Populations From Single-session Transcranial Direct Current Stimulation (tDCS). Brain Stimulation2015:535-50.

103. Grossman N, Bono D, Dedic N, et al. Noninvasive Deep Brain Stimulation via

Temporally Interfering Electric Fields. Cell 2017;169:1029-41.e16.

104. Hess RD, Torney-Purta JV. The Development of Political Attitudes in Children. Chicago: Chicago, Aldine Pub. Co; 1967.

105. Jennings MK, Niemi RG. The Transmission of Political Values from Parent to Child. Am Polit Sci Rev 1968;62:169-84.

106. Sapiro V. NOT YOUR PARENTS' POLITICAL SOCIALIZATION: Introduction for a New Generation. Annual Review of Political Science 2004;7:1-23.

107. Kagan J. Biology, Context, and Developmental Inquiry. Annu Rev Psychol 2003;54:123. 
108. Baron-Cohen S, Tager-Flusberg H, Lombardo M. Understanding other minds:

Perspectives from developmental social neuroscience. 2013.

109. Hatemi PK, Funk C, Medland S, et al. Genetic and Environmental Transmission of Political Attitudes Over a Life Time. Journal of Politics 2009;71:1141-56.

110. Happé F, Frith U. Annual Research Review: Towards a developmental neuroscience of atypical social cognition. J Child Psychol Psychiatr 2013;55:553-77.

111. Santos A, Meyer-Lindenberg A, Deruelle C. Absence of racial, but not gender, stereotyping in Williams syndrome children. Curr Biol 2010;20:R307-8.

112. Kurzban R, Tooby J, Cosmides L. Can race be erased? Coalitional computation and social categorization. Proc Natl Acad Sci U S A 2001;98:15387-92.

113. Balconi M, Vanutelli ME. Competition in the Brain. The Contribution of EEG and fNIRS Modulation and Personality Effects in Social Ranking. Front Psychol 2016;7.

114. van der Zwaag W, Da Costa SE, Zürcher NR, Adams RB, Hadjikhani N. A 7 Tesla fMRI Study of Amygdala Responses to Fearful Faces. Brain Topogr 2017;25:125-8.

115. T Vu A, Jamison K, Glasser MF, et al. Tradeoffs in pushing the spatial resolution of fMRI for the 7T Human Connectome Project. NeuroImage 2017;154:23-32.

116. Beisteiner R, Robinson S, Wurnig M, Hilbert M. Clinical fMRI: evidence for a 7 T benefit over 3T. NeuroImage 2011.

117. Yoo PE, John SE, Farquharson S, Cleary JO, Wong YT. 7T-fMRI: Faster temporal resolution yields optimal BOLD sensitivity for functional network imaging specifically at high spatial resolution. NeuroImage 2017.

118. Vul E, Harris C, Winkielman P, Pashler H. Puzzlingly High Correlations in fMRI Studies of Emotion, Personality, and Social Cognition. Perspectives on Psychological Science 2009;4:274-90.

119. Pereira F, Mitchell T, Botvinick M. Machine learning classifiers and fMRI: a tutorial overview. NeuroImage 2009.

120. Norman KA, Polyn SM, Detre GJ, Haxby JV. Beyond mind-reading: multi-voxel pattern analysis of fMRI data. Trends Cogn Sci 2006;10:424-30.

121. Henson R. Forward inference using functional neuroimaging: dissociations versus associations. Trends Cogn Sci 2006;10:64-9.

122. Poldrack RA. Can cognitive processes be inferred from neuroimaging data? Trends Cogn Sci 2006;10:59-63.

123. Theodoridis A, Nelson A. Of BOLD claims and excessive fears: A call for caution and patience regarding political neuroscience. Political Psychology 2012;33:27-43.

124. Haxby JV, Gobbini MI, Furey ML, Ishai A, Schouten JL, Pietrini P. Distributed and overlapping representations of faces and objects in ventral temporal cortex. Science 2001;293:2425-30.

125. Kay KN, Naselaris T, Prenger RJ, Gallant JL. Identifying natural images from human brain activity. Nature 2008;452:352-5.

126. Huth AG, Lee T, Nishimoto S, Bilenko NY, Vu AT, Gallant JL. Decoding the Semantic Content of Natural Movies from Human Brain Activity. Front Syst Neurosci 2016;10.

127. Berkman ET, Falk EB. Beyond Brain Mapping: Using Neural Measures to Predict RealWorld Outcomes. Current Directions in Psychological Science 2013;22:45-50.

128. Falk EB, Berkman ET, Mann T, Harrison B, Lieberman MD. Predicting persuasioninduced behavior change from the brain. J Neurosci 2010;30:8421-4. 
129. Falk EB, Berkman ET, Whalen D, Lieberman MD. Neural activity during health messaging predicts reductions in smoking above and beyond self-report. Health psychology : official journal of the Division of Health Psychology, American Psychological Association 2011;30:177-85.

130. Lieberman MD, Gaunt R, Gilbert DT, Trope Y. Reflection and Reflexion: A Social Cognitive Neuroscience Approach to Attributional Inference. Advances in Experimental Social Psychology 2002;34:199-249.

131. Kahneman D. Thinking, fast and slow. 1st pbk. ed. New York: Farrar, Straus and Giroux; 2013.

132. Falk EB, Berkman ET, Lieberman MD. From neural responses to population behavior: neural focus group predicts population-level media effects. Psychological science : a journal of the American Psychological Society / APS 2012;23:439-45.

133. Genevsky A, Knutson B. Neural Affective Mechanisms Predict Market-Level Microlending. Psychological Science : a journal of the American Psychological Society / APS 2015;26:1411-22.

134. Venkatraman V, Dimoka A, Pavlou PA. Predicting Advertising Success Beyond Traditional Measures: New Insights from Neurophysiological Methods and Market Response Modeling. Journal of Marketing Research 2015.

135. Randall K. Neuropolitics, Where Campaigns Try to Read Your Mind. New York Times2015.

136. Malkin E, Randall K. Mexico's Governing Party Vows to Stop Using Neuromarketing to Study Voters. New York Times2015.

137. Varshney L, Chen B, Paniagua E, Hall D, Chklovskii D. Structural Properties of the Caenorhabditis elegans Neuronal Network. PLoS Comput Biol 2011;7:e1001066.

138. Wade N. In Tiny Worm, Unlocking Secrets of the Brain. New York Times 2011:D1. 